NOTE

\title{
Fatty acid biomarkers reveal niche separation in an Arctic benthic food web
}

\author{
Suzanne M. Budge ${ }^{1, *}$, Alan M. Springer ${ }^{2}$, Sara J. Iverson ${ }^{3}$, Gay Sheffield ${ }^{4}$ \\ ${ }^{1}$ Department of Process Engineering and Applied Science, Dalhousie University, Halifax, Nova Scotia B3J 2X4, Canada \\ ${ }^{2}$ Institute of Marine Sciences, University of Alaska Fairbanks, Fairbanks, Alaska 99775, USA \\ ${ }^{3}$ Department of Biology, Dalhousie University, Halifax, Nova Scotia B3H 4J1, Canada \\ ${ }^{4}$ Alaska Department of Fish and Game, Fairbanks, Alaska 99701, USA
}

\begin{abstract}
Marine fatty acids (FA) are synthesized primarily by phytoplankton and have a wide variety of structures. Biochemical restrictions on the synthesis or modification of FA in animals make it possible to recognize those derived from their prey; numerous studies have demonstrated the transfer of FA from prey to predator at various trophic levels. Although rarely occurring, a few FA found in animals, including the $\mathrm{C}_{20}$ and $\mathrm{C}_{22}$ non-methylene-interrupted (NMI) FA, can be traced to quite specific prey types. These unusual lipids are synthesized de novo by certain benthic mollusks, particularly bivalves, through chain elongation and desaturation of common monounsaturated FA precursors. Their proportions vary among species, suggesting that they might be particularly suitable as biomarkers in food web studies. We recently discovered NMI FA in 2 species of sympatric, benthicfeeding pinnipeds in Alaska, bearded seals Erignathus barbatus and Pacific walruses Odobenus rosmarus. Significant differences in proportions of 6 NMI FA, and patterns of other FA, demonstrated considerable dietary separation between the bearded seals and walruses. This is the first report of NMI FA in marine mammals, and the first use of these specific FA biomarkers in evaluating trophic pathways in mammals. These individual FA biomarkers, together with suites of other FA, have wide application in understanding marine food webs, including those in the Arctic where rapid environmental change threatens fragile ecosystems.
\end{abstract}

KEY WORDS: Fatty acids · Non-methylene interrupted $\cdot$ Trophic ecology $\cdot$ Bearded seals $\cdot$ Walruses Diet

\section{INTRODUCTION}

Bearded seals Erignathus barbatus and Pacific walruses Odobenus rosmarus in the Bering and Chukchi Seas occupy similar habitats, are closely associated with sea ice and have overlapping ranges (Fay 1982, Simpkins et al. 2003). There are no estimates of their current abundances or recent population trends, but there is concern that both species are in jeopardy because of the declining extent and duration of seasonal sea ice in the Western Arctic (Tynan \& DeMaster
1997). Both species feed on a variety of benthic invertebrates, among which clams, snails, and crabs are particularly important; at times bearded seals also consume large amounts of benthic and pelagic fishes (Lowry et al. 1980, Antonelis et al. 1994, Sheffield 1997). Their overlapping range, habitat use, and dietary associations have led to speculation that competition for shared prey, in particular the mollusk Serripes sp., might have adverse consequences for one or both species (Lowry et al. 1980). Changes in benthic community structure, and declining benthic biomass 
and productivity in recent years in the northern Bering Sea, reveal broad ecosystem processes that are likely to have important ramifications for bearded seals and walruses, as well as other species at high trophic levels which use this area during the winter months (Grebmeier et al. 2006).

Previous studies of bearded seal and walrus diets in Alaska have been based on the analysis of stomach contents. However, methods that rely on the recovery of parts resistant to digestion are subject to known biases, some of which can be corrected, while others continue to limit the value of the information obtained (Jobling \& Breiby 1986). For example, based on the analysis of stomach contents, it was long believed that walruses consumed primarily the siphons of clams (Fay 1982). However, more recently Sheffield (1997) have shown that whole bivalves are ingested; the soft parts of the bodies of clams are quickly digested, leaving the more robust siphons to be enumerated. Likewise, prey species with soft bodies, such as priapulid and sipunculid worms and sea cucumbers, are also digested rapidly and were greatly under-represented in earlier analyses. Certainly, such biases make diet evaluations based on the analysis of stomach contents problematic in these mammals.

An alternative to using stomach contents for estimating diet is the analysis of fatty acids (FA) found in reservoir lipids. Marine FA have a wide variety of structures and, because of biochemical restrictions on the synthesis of FA in marine predators, it is possible to recognize FA derived from their prey. Thus, dietary FA are useful as indicators, or biomarkers, of their source and can provide an integrated record of diet over time. Several studies have demonstrated the transfer of FA from prey to predator both at the bottom of the food web (e.g. Fraser et al. 1989), and near the top (e.g. Iverson et al. 1997, Kirsch et al. 2000). Because most FA structures are common to a variety of organisms, it is usually very difficult to find unique FA biomarkers for specific sources. However, an exception to this may be the $\mathrm{C}_{20}$ and $\mathrm{C}_{22}$ non-methylene-interrupted (NMI) FA of benthic mollusks. FA typically contain a single methylene $\left(\mathrm{CH}_{2}\right)$ group between double bonds; NMI FA contain more then one methylene group between double bonds. These unusual FA have been identified in a range of benthic invertebrates and appear to be found in all bivalves and carnivorous gastropods (Joseph 1982 and references therein). Their limited presence in the depot fats of higher predators, such as finfish, led Paradis \& Ackman (1977) to suggest that NMI FA might be particularly suitable as biomarkers in food web studies. The relative proportions of NMI FA vary with the species examined (e.g. Howell et al. 2003, Castell et al. 2004, Kraffe et al. 2004), indicating that they might have application in differentiating between principle food items in the diet of higher predators. Thus, NMI FA may be particularly useful in resolving the questions of resource competition between bearded seals and walruses, which specialize on mollusks. In this study, we examined the FA composition of blubber of bearded seals and walruses collected at the same time from the same location in the northern Bering Sea. Our objectives were (1) to investigate the use of NMI FA as specific biomarkers of different prey types in the diets of the 2 species, and (2) to evaluate the potential level of competition between these 2 species for shared prey using a suite of NMI and other FA.

\section{MATERIALS AND METHODS}

Sample source and extraction. Blubber samples were collected from bearded seals $(n=25)$ and Pacific walruses $(n=9)$ taken in May and June of 2002 by subsistence hunters on Little Diomede Island, Alaska $\left(65.75^{\circ} \mathrm{N}, 168.95^{\circ} \mathrm{W}\right)$. Samples were collected within $24 \mathrm{~h}$ of the animals' death. Bearded seal samples consisted of a mixture of adults and sub-adults. All of the walrus samples were adult females. Blubber samples (approximately 100 to $300 \mathrm{~g}$ ) represented the entire thickness of the blubber layer, with skin and muscle attached. Whole samples were frozen at $-20^{\circ} \mathrm{C}$ until analyzed. A longitudinal slice $(\sim 0.5 \mathrm{~g})$ was removed from each blubber sample, excluding skin and muscle. Lipids were quantitatively extracted and fatty acid methyl esters (FAME) were prepared directly from the extracted lipid using methods described in Budge et al. (2006).

Chromatography. FAME were analyzed in duplicate using temperature-programmed gas chromatography on a Perkin Elmer Autosystem II capillary gas chromatograph (GC) with a flame ionization detector (FID) using a polar column (Agilent Technologies, DB-23; $30 \mathrm{~m} \times 0.25 \mathrm{~mm}$ ID) according to Budge et al. (2006). Up to 66 FAME were routinely identified according to Iverson et al. (1997) and are reported as weight percent of total fatty acids (FA) identified. Unusual nonmethylene-interrupted (NMI) FA were identified using silver nitrate chromatography and GC-mass spectrometry. On the DB-23 column employed, NMI FA $20: 2 \Delta 5,11$ and $20: 2 \Delta 5,13$ eluted immediately before and after $20: 2 n-9 ; 20: 3 \Delta 5,11,14$ was located just before 20:3n-6; and 22:2NMID (double bond positions not identified), $22: 2 \Delta 7,13$ and $22: 2 \Delta 7,15$ eluted as a trio of peaks immediately after 22:1n-7. These NMI FA are prominent in common bivalves such as Mytilus edulis so extracts of that bivalve were used as laboratory standards to assist in the identification of the NMI FA in blubber samples. 
Statistics. To investigate the variation in blubber FA composition between bearded seals and walruses, Bray-Curtis similarity matrices were calculated on the dataset consisting of all FA present at proportions $>0.1 \%$ and analysis of similarity (ANOSIM) was preformed using PRIMER 6 (Primer-E). Significant differences in FA profiles were identified using the global $\mathrm{R}$ values, and a similarity percentages routine (SIMPER) was used to determine the FA contributing to the differences. To improve normality, FA data were transformed using an arcsine square root function.

\section{RESULTS AND DISCUSSION}

\section{General fatty acid characteristics}

Analysis of similarity (ANOSIM), using age and sex as factors, did not indicate a significant difference among FA profiles of bearded seals. This is consistent with reports of bearded seal diets using analyses of stomach contents (Lowry et al. 1980, Antonelis et al. 1994). Thus, all bearded seal FA data were treated as a single group in subsequent analyses.

The FA composition of blubber from both bearded seals and Pacific walruses was characterized by high levels of monounsaturated FA (54 to $57 \%$ ), particularly 16:1n-7, 18:1n-9, and 18:1n-7 (Fig. 1a). Total proportions of saturated and polyunsaturated fatty acids (PUFA) were also quite similar between the 2 species at 14 to $15 \%$ and 27 to $29 \%$ of total FA, respectively. However, ANOSIM indicated an overall difference in proportions $(\mathrm{R}=0.80, \mathrm{p}<0.001)$ between the bearded seals and walruses, with 20:1n-9, 20:1n-7, 22:5n-3 and 22:6n-3 principally responsible for the differences (Fig. 1a). The key differences in the FA ratios between the 2 species are shown in Fig. 1a. For example, in bearded seal blubber, proportions (and ratios) were: $18: 1 n-9>18: 1 n-7$ (1.7), 20:1n-9 $\cong 20: 1 n-7$ (1.0), and $22: 6 n-3>22: 5 n-3$ (1.6). In contrast, for walruses: $18: 1 n-$ $9 \cong 18: 1 \mathrm{n}-7$ (1.0), $20: 1 \mathrm{n}-9<20: 1 \mathrm{n}-7$ (0.2), and 22:6n-3 $<22: 5 n-3(0.6)$.

The general FA composition of bearded seal blubber is consistent with previous reports (West et al. 1979a, Durnford \& Shahidi 2002), particularly in terms of PUFA levels. However, in both of these earlier studies, samples sizes were very low ( $\mathrm{n}=2$ and 3 , respectively) and not all FA were identified or reported. For instance, neither study reported the presence of NMI FA or the 3 isomers of 20:1 and 22:1. Although we did not have prey items for analysis, bearded seal diets likely include a variety of benthic mollusks as well as pelagic and demersal fish (e.g. Lowry et al. 1980, Antonellis et al. 1994). In contrast to bearded seals, walrus are believed to consume a diet consisting

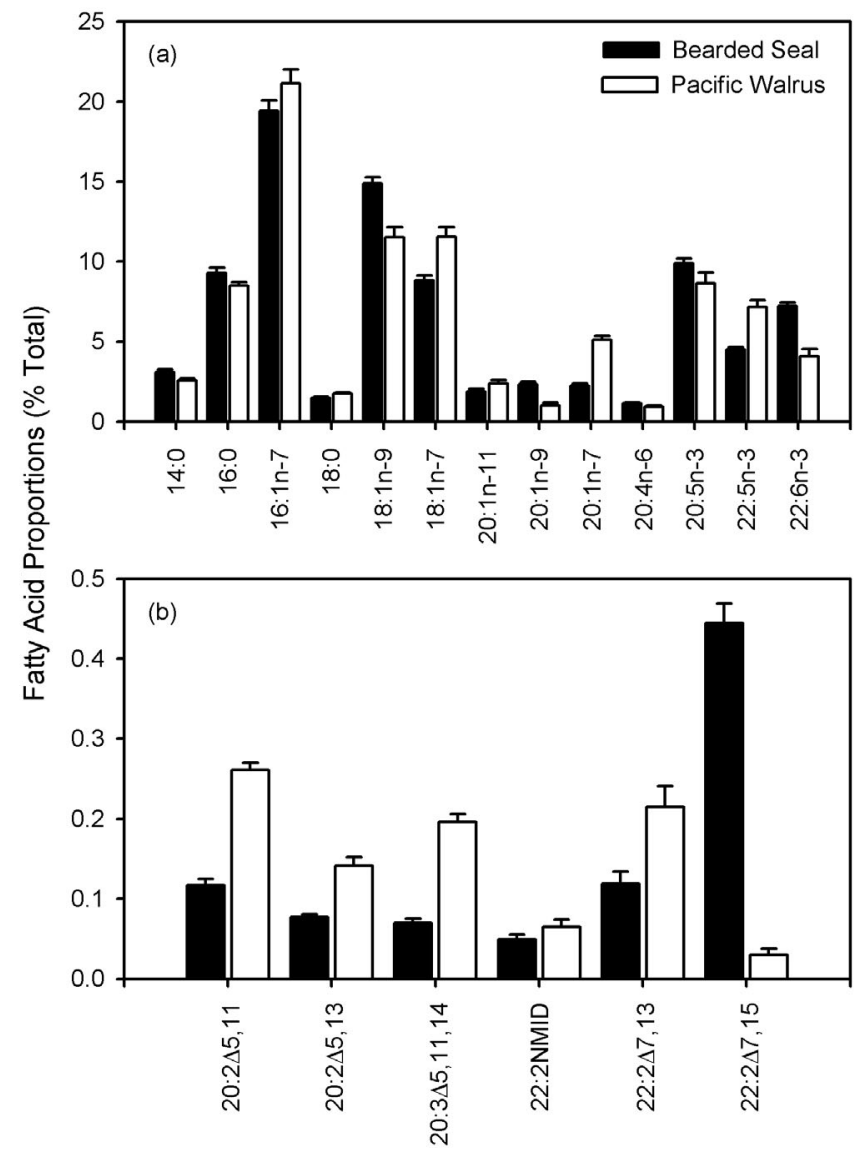

Fig. 1. Erignathus barbatus and Odobenus rosmarus. Proportions (mean $\pm \mathrm{SE}$ ) of (a) major ( $>1 \%$ ) fatty acids (FA) exhibiting the greatest variance and (b) non-methylene-interrupted (NMI) FA in bearded seals and Pacific walruses. Blubber FA differed significantly between species (ANOSIM: $\mathrm{R}=0.80, \mathrm{p}<$ 0.001 ), with $20: 1 n-9,20: 1 n-7,22: 5 n-3$ and $22: 6 n-3$ principally responsible for the difference. NMI FA, with the exception of 22 : 2 NMID, also differed significantly $(\mathrm{R}=0.63, \mathrm{p}<0.001)$. The full FA dataset is available upon request

almost exclusively of benthic mollusks (Fay 1982, Sheffield 1997). The elevated proportions of $n-7$ relative to n-9 isomers of the 18, 20 and 22 carbon monounsaturated FA in walrus blubber (Fig. 1a) is unique among marine mammals (e.g. Iverson et al. 1997, Durnford \& Shahidi 2002), and can likely be attributed to a diet rich in mollusks. These same FA characteristics are typical of many species of mollusks (Joseph 1982) and suggest their direct deposition into walrus blubber. The only other study of Pacific walrus blubber FA composition (West et al. 1979b) did not report the unusually large proportions of 18:1n-7 and 20:1n-7 found here, as only one isomer of each monounsaturated FA was identified. NMI FA were also not identified in the previous study of walrus blubber (West et al. 1979b). 


\section{Non-methylene-interrupted fatty acid (NMI FA) biomarkers}

The sum of the 6 NMI FA percentages in both species is at a level approaching $1 \%$ of the total FA (Fig. 1b). Although both bearded seals and walruses contained similar total levels of NMI FA (0.88 to $0.91 \%$ of total FA), amounts of specific NMI FA differed significantly between species $(\mathrm{R}=0.63, \mathrm{p}<0.001)$. The bearded seal NMI FA profile was dominated by $22: 2 \Delta 7,15$ at $0.45 \%$ of total FA or $51 \%$ of total NMI FA, with amounts of the other NMI FA each accounting for 5 to $14 \%$ of total NMI FA (Fig. 1b). In the walrus, the dominant NMI FA in bearded seals $(22: 2 \Delta 7,15)$, was only present at trace levels $(0.03 \%$ of total FA or only $3 \%$ of total NMI FA), while $20: 2 \Delta 5,11,20: 3 \Delta 5,11,14$, and $22: 2 \Delta 7,13$ each represented 22 to $30 \%$ of total NMI FA.

NMI FA have been found in bivalves, gastropods, chitons, sea urchins and sea stars (Joseph 1982, Castell et al. 2004, Kraffe et al. 2004), but appear to be produced only by the herbivorous/detritivorous species, such as clams and mussels, through de novo synthesis from chain elongation and $\Delta 5$ desaturation of the common precursors 16:1n-7 and 18:1n-9 (Zhukova 1991). In predatory benthic organisms, such as some snails and sea stars, NMI FA likely accumulate from their diet, as they do in bearded seals and walruses. In either case, by synthesis or accumulation, levels of these FA vary among benthic mollusks and the invertebrate species that prey upon them. For example, in an early study where individual NMI FA isomers were not separated (Paradis \& Ackman 1977), the mussel, Mytelis edulis, had much higher levels of 20:2 NMI FA than 22:2 NMI FA, while the oyster, Crassostrea virginica, collected in a similar location, had lower levels of 20:2 NMI FA than 22:2 NMI FA. More recently, Howell et al. (2003) have shown variation in levels of individual NMI FA in a number of predatory sea stars. These reports and others (e.g. Joseph 1982, Castell et al. 2004, Kraffe et al. 2004) indicate that NMI FA levels in mollusks and their benthic invertebrate predators are species specific.

The presence of NMI FA in the depot fats of benthic feeding bearded seals and walruses was expected; however, the NMI FA that dominated in one species were only present at low levels in the other (Fig. 1b). If we assume that NMI FA are metabolized across species following similar pathways, as are regular, methylene-interrupted FA, then we can conclude that bearded seals in this study were consuming a diet high in species which contained elevated amounts of $22: 2 \Delta 7,15$ relative to the other NMI FA. In contrast, walruses were consuming other prey that contained much less of that FA and comparatively higher levels of most of the other NMI FA. This strongly suggests that the 2 pinnipeds were not feeding to a large extent on the same prey that either produce or accumulate NMI FA. The known or potential species available to bearded seals and walruses that contain NMI FA and are important prey for one or both in the northern Bering Sea, include the clams Serripes sp., Mya sp., Hiatella sp., and Macrometris sp. and the predatory snails Polinices sp., Neptunea sp., and Nautica sp. (Sheffield 1997). There is clearly at least some niche separation between these 2 pinnipeds in consumption of those benthic mollusks. Other species preyed upon by either or both bearded seals and walruses, particularly crabs, shrimps, marine worms, and fishes, are not known to produce or accumulate NMI FA, except perhaps in trace amounts (e.g. Paradis \& Ackman 1977).

Lowry et al. (1980) suggested that a dramatic increase in the walrus population in the 1940s through the 1970s and a change in their distribution led to the depletion of the clam Serripes sp., one of the primary prey of both bearded seals and walruses in the northern Bering Sea. They speculated that the depletion explained an apparent decline in consumption of Serripes sp. by bearded seals in the vicinity of the Diomede Islands from the late 1950s through the 1970s. Given the contrasting NMI FA profiles of bearded seals and walruses, they both could not be consuming similar amounts of Serripes sp. The overall profile of more usual and abundant FA further suggests that diets differ in significant ways and, together with NMI FA, demonstrate a large degree of resource partitioning between bearded seals and walruses in the same region.

This is the first report of NMI FA in any marine mammal. Presumably, these FA have been largely overlooked because of their low concentrations at less than $0.5 \%$ of total FA. The specific sources and unusual structures of NMI FA make them unique as biomarkers to indicate different feeding patterns in marine mammals. Given the resolution currently possible with polar capillary gas chromatograph columns that are in pristine condition, these unusual FA can be accurately and reliably identified and quantified. We suggest that the addition of NMI FA to the FA signatures used in more complex diet modeling in marine mammals can only increase the accuracy of diet estimates. NMI FA may be especially useful in the Arctic for tracing patterns and change in diets of species dependent on benthic production, such as bearded seals and walruses, and of polar bears and killer whales that prey upon them. Rapid environmental change is jeopardizing numerous animals in the Arctic, and novel tools such as NMI FA biomarkers should be important in describing niche space of species at higher trophic levels and predicting long term consequences to fragile ecosystems. 
Acknowledgements. We are indebted to the hunters at Little Diomede Island for providing samples from bearded seals and walruses taken in their subsistence hunts. Seal specimen collections were authorized by National Marine Fisheries Service Scientific Research Permit 358-1585. Funding for this project was provided by the Cooperative Institute for Arctic Research. Additional support came from the National Science Foundation (Grant \# OPP 9910319) and the Natural Sciences and Engineering Research Council (NSERC) of Canada.

\section{LITERATURE CITED}

Antonelis GA, Melin SR, Bukhtiyarov YA (1994) Early spring feeding habits of bearded seals (Erignathus barbatus) in the Central Bering Sea, 1981. Arctic 47:74-79

Budge SM, Iverson SJ, Koopman HN (2006) Studying trophic ecology in marine ecosystems using fatty acids: a primer on analysis and interpretation. Mar Mamm Sci 22:759-801

Castell JD, Kennedy EJ, Robinson SMC, Parsons GJ, Blair TJ, Gonzalez-Duran E (2004) Effect of dietary lipids on fatty acid composition and metabolism in juvenile green urchins (Strongylocentrotus droebachiensis). Aquaculture 242:417-435

Durnford E, Shahidi F (2002) Comparison of FA compositions of selected tissues of phocid seals of eastern Canada using one-way and multivariate techniques. J Am Oil Chem Soc 79:1095-1102

Fay FH (1982) Ecology and biology of the Pacific walrus, Odobenus rosmarus divergens Illiger. N Am Fauna 74: $1-279$

Fraser AJ, Sargent JR, Gamble JC, Seaton DD (1989) Formation and transfer of fatty acids in an enclosed food chain comprising phytoplankton, zooplankton and herring $(\mathrm{Clu}-$ pea harengus) larvae. Mar Chem 27:1-18

Grebmeier JM, Overland JE, Moore SE, Farley EV and 6 others (2006) A major ecosystem shift in the northern Bering Sea. Science 311:1461-1464

Howell KL, Pond DW, Billett DSM, Tyler PA (2003) Feeding ecology of deep-sea seastars (Echinodermata: Asteroidea): a fatty-acid biomarker approach. Mar Ecol Prog Ser 255:

Editorial responsibility: Howard Browman (Associate Editorin-Chief), Storebø, Norway
193-206

Iverson SJ, Frost KJ, Lowry LF (1997) Fatty acid signatures reveal fine scale structure of foraging distribution of harbor seals and their prey in Prince William Sound, Alaska. Mar Ecol Prog Ser 151:255-271

Jobling M, Breiby A (1986) The use and abuse of fish otoliths in studies of feeding habits of marine piscivores. Sarsia 71: $265-274$

Joseph JD (1982) Lipid composition of marine and estuarine invertebrates. Part II: Mollusca. Prog Lipid Res 21:109-153

Kirsch PE, Iverson SJ, Bowen WD (2000) Effect of diet on body composition and blubber fatty acids in captive harp seals (Phoca groenlandica). Physiol Biochem Zool 73:45-59

Kraffe E, Soudant P, Marty Y (2004) Fatty acids of serine, ethanolamine, and choline plasmalogens in some marine bivalves. Lipids 39:59-66

Lowry LL, Frost KJ, Burns JJ (1980) Feeding of bearded seals in the Bering and Chukchi Seas and trophic interaction with Pacific walruses. Arctic 33:330-342

Paradis M, Ackman RG (1977) Potential for employing the distribution of anomalous nonmethylene-interrupted dienoic fatty acids in several marine invertebrates as part of food web studies. Lipids 12:170-176

Sheffield G (1997) Walrus feeding: a re-examination. MSc dissertation, University of Alaska

Simpkins MA, Hiruki-Raring LM, Sheffield G, Grebmeier JM, Bengtson JL (2003) Habitat selection by ice-associated pinnipeds near St. Lawrence Island, Alaska in March 2001. Polar Biol 26:577-586

Tynan CT, DeMaster DP (1997) Observations and predictions of Arctic climate change: Potential effects on marine animals. Arctic 50:308-322

West GC, Burns JJ, Modafferi M (1979a) Fatty acid composition of blubber from the four species of Bering Sea phocid seals. Can J Zool 57:189-195

West GC, Burns JJ, Modafferi M (1979b) Fatty acid composition of Pacific walrus skin and blubber fats. Can J Zool 57: 1249-1255

Zhukova NV (1991) The pathway of the biosynthesis of nonmethylene-interrupted dienoic fatty acids in molluscs. Comp Biochem Physiol B 100:801-804

Submitted: March 16, 2006; Accepted: October 6, 2006 Proofs received from author(s): April 5, 2007 